\title{
"Si tiras basura provocas inundaciones": Niñas y niños en la construcción de conocimiento ambiental en clases de educación primaria
}

\author{
"If you litter you'll cause floods": Children and the construction \\ of environmental awareness in elementary school classrooms
}

DOI: https://doi.org/10.32870/dse.v0i20.604

\section{Erik S. Lara Corro*}

\begin{abstract}
Resumen
¿Qué dicen y hacen niñas y niños acerca de, por ejemplo, cuestiones ambientales? ¿Qué construyen a partir de su "saber común" en relación con los contenidos curriculares? ¿Qué inquietudes y creencias movilizan en las aulas? Son algunas de las preguntas que nutren el interés por comprender el sentido que los estudiantes asignan al contenido escolar en sus narrativas sobre los sucesos de la vida diaria. Desde un enfoque etnográfico, analizo cómo en las interacciones niñas y niños construyen conocimiento ambiental cuando movilizan sus explicaciones de esos contenidos prescritos. Por ejemplo, consideran que el ambiente se daña porque "compramos muchas cosas" y "tiramos basura". También expresan opiniones (críticas) sobre los hábitos de los adultos: "tiran basura en las calles" o "no separan sus desechos". Estas situaciones que se trasladan en las salas de clase dan cuenta de la apropiación de diversos discursos ambientales, particularmente sobre las prácticas cotidianas de las personas, la atribución de responsabilidades de la contaminación ambiental y la generación de hábitos considerados benéficos para el ambiente. Además, estos aspectos evidencian cierta socialización pública de los problemas ambientales, que podrían ubicarse en el marco de hábitos de consumo y desecho de residuos ocasionados por un factor sistémico.
\end{abstract}

Palabras clave: participación de estudiantes - construcción de conocimiento - educación ambiental escuelas primarias - etnografía.

\begin{abstract}
What children say and do about, for example, environmental topics? What do they build from the "common knowledge" they bring to school in relation to curricular content? What concerns and beliefs do they mobilize in the classroom? These are some of the questions behind our interest in understanding the meaning that students assign to curricular content in their narratives about the events of daily life. From an ethnographic approach, I analyze how children build environmental knowledge when they mobilize their explanations of these contents
\end{abstract}

* Doctorante en Antropología. Becario CONICET en el Centro de Estudios Desigualdades, Sujetos e Instituciones (CEDESI-UNSAM), Buenos Aires, Argentina.elara@unsam.edu.ar 
in their interactions. For example, they believe that the environment is damaged because "we buy many things" and "litter". They also express (critical) opinions about the habits of adults: "they throw garbage in the streets" or "they don't separate their waste". These situations that are brought to the classrooms show the appropriation of environmental discourses, particularly on people's daily practices, the attribution of responsibility for environmental pollution, and the generation of habits considered beneficial for the environment. Also, these aspects show some public socialization of environmental problems, which might be seen in a context of consumption and waste disposal habits caused by a systemic factor.

Keywords: participation of children - knowledge construction - environmental education - elementary schools - ethnography.

\section{Introducción}

El campo de la educación ambiental (EA) es un espacio de continuos debates y significaciones que históricamente han dado pauta a diversos proyectos sobre lo que "deberían aprender" las personas para vivir en armonía con y en el ambiente. En la cotidianidad de algunas aulas de escuelas primarias públicas, la contaminación por basura es uno de los problemas más reconocidos (Lara Corro, 2018). ${ }^{1}$ Este tipo de temas, en algunos casos surgen como preocupaciones tanto del currículo escolar como de docentes y estudiantes, producto del debate público y científico que se filtra en los salones de clases acerca de las problemáticas sociales y ambientales. Incluso, se relacionan con los patrones de consumo en las sociedades capitalistas y de la acción humana en el espacio social y natural, sobre todo aquella que es observable por niñas y niños. ${ }^{2}$ Por ejemplo, los hábitos que llevan a cabo en sus hogares y otros espacios (como la calle, los parques o las plazas públicas) para "cuidar el ambiente", o cuestionar ciertas prácticas del mundo adulto: "tiran basura en las calles", "arrojan cosas porque compran y compran"y"no separan sus desechos".

En este artículo analizo cómo, en las dinámicas de interacción, los estudiantes construyen conocimiento de los contenidos curriculares de EA. Para ello, centro la mirada en las prácticas y los discursos de estudiantes y docente en el desarrollo del Proyecto Ambiental en Educación Primaria. ${ }^{3}$ Este es un trabajo entendido como etnográfico, conformado por un proceso de construcción largo y complejo que se caracteriza por la imbricación entre el trabajo teórico y la tarea descriptiva (Rockwell, 2009). Estas particularidades me permitieron dar cuenta de la complejidad sobre lo que sucede en los

1 Este trabajo es producto de una investigación más amplia, realizada en el programa de maestría del Departamento de Investigaciones Educativas del CINVESTAV (México). En la tesis "La construcción social de conocimiento ambiental en aulas de escuelas primarias", con el acompañamiento de la Dra. Antonia Candela, analizé los conocimientos ambientales que estudiantes y profesores construyeron en la dinámica de interacción en aulas de dos escuelas primarias de la Ciudad de México.

2 De ahora en adelante emplearé genéricamente la palabra "niños" para referir también a las niñas.

3 En el plan de estudios 2011 de la Secretaría de Educación Pública se plantean 12 principios pedagógicos que lo sustentan. Uno de ellos es"incorporar temas de relevancia social", en atención, entre otros temas, a la educación ambiental para la sustentabilidad (SEP, 2011a). A partir de la construcción de proyectos integradores, la profesora Perla planteó el Proyecto Ambiental en Educación Primaria, interrelacionando los temas “¿Adónde va la basura?" (72-73) y la Lección 6"¿De dónde viene la basura?" (30-31), del libro de Ciencias Naturales de tercer grado.

Diólo pos sobre Educación año 11 | número 20 | enero-junio 2020| ISSN 2007-2171 
salones de clases y del trabajo cotidiano de los actores educativos. Para ello, me involucré en la cotidianidad de una escuela primaria pública, la "Zapata". Esto me acercó a la experiencia escolar cotidiana, con la intención de comprender sus dinámicas y "hacer visible" cómo funciona el proceso de educación ambiental en las escuelas a partir del seguimiento, la reconstrucción y el análisis de situaciones reales de interacción.

El trabajo de campo fue realizado en el primer semestre de 2015. La escuela Zapata es de jornada completa y está situada en una zona urbana -entre los márgenes de Tlalpan y Coyoacán, aunque jurisdiccionalmente pertenece a esta última — de la Ciudad de México. La población correspondiente a esta área se dedica sobre todo al comercio, actividades de servicios o la administración pública. Algunos estudiantes me dijeron que sus familiares son taxistas, comerciantes, obreros o profesionistas. El salón de clases donde trabajé es medianamente pequeño. El aula está equipada con una computadora ${ }^{4}$ con parlantes, proyector multimedia, pizarrón electrónico y pupitres individuales. Con respecto a la organización del tiempo, las sesiones de clase son de 50 minutos aproximadamente.

Documenté clases de un grupo de cuarto grado, conformado por 36 estudiantes (21 niñas y 15 niños) entre 9 y 11 años, atendidos por su maestra Perla. ${ }^{5}$ Ella realizó sus estudios en la Benemérita Escuela Nacional de Maestros (en el Plan de estudios 1993). Lleva 15 años trabajando como profesora y solo uno en la escuela actual. Ha tomado cursos sobre la enseñanza de EA. El corpus de información empírica lo obtuve de 11 videograbaciones de sesiones de clases. También realicé notas de las conversaciones con la docente, para comprender su propia práctica pedagógica, y con algunos estudiantes. Seleccioné los registros donde había riqueza de elementos en la dinámica de interacción entre los alumnos y la maestra. Muestro situaciones donde los participantes otorgan sentidos del contenido ambiental y describo las interacciones tratando de reducir lo menos posible su complejidad. Dirijo la mirada a situaciones donde las interacciones se centran en conocimientos ambientales, más que en la organización per se de las actividades. Aquí, el análisis etnográfico de lo que sucedió a nivel de las clases me permitió "comprender la práctica educativa desde la perspectiva de los propios actores" (Candela, 1999b: 5).

El proceso que viví en esta cotidianidad particular me permitió descentrarme de una visión prescriptiva de la operación de la norma oficial, la cual representa el eslabón que une los programas educativos y las prácticas cotidianas (Rockwell, 1995b). Por lo tanto, presento lo que ocurre en el espacio social de las aulas evitando evaluar las consecuencias de las políticas educativas, las prescripciones pedagógicas, la enseñanza en función de algún parámetro ideal o lo "aprendido" por los niños. La realización de estos estudios permite conocer procesos escolares cotidianos diversos; en este caso, cómo el contenido ambiental es vivido por los actores educativos.

4 Algunas de esas computadoras fueron usadas anteriormente para el programa Enciclomedia.

5 Con el fin de proteger el anonimato de los niños y la docente, utilizo nombres ficticios a lo largo de este escrito. 


\section{El lugar de niñas y niños en la construcción de conocimiento ambiental}

En nuestro país, la educación ambiental (EA) ha encontrado espacios curriculares reconocidos. Es un campo que surgió como una necesidad urgente, a pesar de los conflictos, intereses y correlaciones de fuerza que se ponen en juego develando, precisamente, aquello que sitúa a algunas disciplinas por encima de otras (Goodson, 1995). En la experiencia nacional, la incorporación de la dimensión ambiental en el currículo de primaria se articuló rápidamente, sin desconocer las disyunciones y las controversias de sus alcances reales y las diversas mediaciones que ha atravesado. ${ }^{6}$ La inclusión de esta dimensión en el currículo de educación básica generó la posibilidad de integrar diversas áreas del conocimiento, disciplinas y saberes para la búsqueda de soluciones a los problemas de manera interdisciplinar. Se propició, de cierta manera, la formación de los sujetos en el conocimiento y la comprensión del ambiente desde un marco social (González Gaudiano, 2007). Pero a pesar de las intervenciones públicas en el nivel curricular, los resultados no han sido del todo satisfactorios, ya que existe una diferenciación clara entre lo que el alumnado conoce de su mundo y lo que en la escuela se presenta como conocimiento "válido" (Rockwell, 1995a). Aquí es importante analizar el vínculo curricular de este campo con los sentidos que le otorgan los actores educativos a esos conocimientos formales, a pesar de la validez científica y pedagógica que pudieran tener. Como señala Enrique Leff, la EA

se inscribe en un proceso de construcción y apropiación de conceptos que generan sentidos divergentes", pues "la diversidad cultural se despliega como una matriz de racionalidades diferenciadas, que resignifican los principios de racionalidad ambiental, arraigándolos en el mundo de vida de cada persona y cada comunidad (Leff, 1998: 209).

En los últimos años, la línea de investigación más desarrollada en didáctica de las ciencias ha sido el estudio de las ideas de los niños sobre los fenómenos de la naturaleza y el análisis del proceso de desarrollo de sus concepciones (Candela, 1990, 2001; Driver, 1983). Antonia Candela explica que, "dependiendo de las situaciones de interacción, los sujetos construyen versiones diversas sobre un contenido" (1999b: 24). Las aulas son el espacio de tradiciones de enseñanza históricamente construidas (Candela, Rockwell y Coll, 2012), de articulación y encuentro de múltiples voces sociales, y donde se producen formas particulares de comunicación, pues el discurso tiene una estructura distinguible y un lenguaje específico (Candela, 1999a). Este espacio social constituye un contexto particular donde, por medio de la interacción, se contrastan y negocian significados locales y específicos sobre los contenidos que se estudian, como los ambientales.

6 Caso contrario a los programas de formación en educación ambiental que han avanzado más lentamente. Esto se traduce en la escasez de profesionales capacitados para elaborar y ejecutar políticas ambientales eficaces (Leff, 1998).

Diálo@os sobre Educación año 11 | número 20 | enero-junio 2020| ISSN 2007-2171 
A saber, en la historia del pensamiento humano, el mundo occidental separó el "saber común" del "saber culto". Por esta razón, el conocimiento es visto predominantemente como dicotómico: local, cotidiano, extraescolar, de sentido común frente al científico y filosófico. Antonio Gramsci (1971) dijo que no es posible separar lo que se llama filosofía "científica" de la filosofía "vulgar y popular", pues solo son un conjunto disgregado de ideas y opiniones. El conocimiento, más que ser objetivo, resulta de la actividad social y del intercambio con otros, pero también depende de un proceso de negociación social que rescata la complejidad de las relaciones y deja de ser un hecho individual (véase Edwards y Mercer, 1988). Es, asimismo, el resultado de una construcción colectiva donde se producen nuestras versiones del mundo. Ningún conocimiento puede liberarse de las propiedades históricas, culturales, sociales y discursivas que lo producen.

Cuando estudiantes y docentes están sujetos a diversas regulaciones sociales e institucionales, ellos son agentes activos con sus propios intereses, propósitos y perspectivas que contribuyen a la constitución de su cotidianidad. Elsie Rockwell (1995: 30) ilustra una crítica sobre cómo se ha pensado el conocimiento, pues "suele concebirse y medirse como posesión o atributo individual". No obstante, los contenidos ambientales no pueden ser trasmitidos como si se tratara de una caja negra que espera ser abierta. Los estudios socioculturales han demostrado que el profesorado interpreta, usa y construye de maneras muy diversas las propuestas de los productores de discursos y normas (Chartier, 1995). Sus aportes son una herramienta que comparte con los participantes del proceso educativo y coloca a los niños en condiciones de replantearse los contenidos que se presentan y movilizan.

Mediante un proceso de co-construcción cotidiana, los sujetos pueden trasformar el sentido de los signos heredados e inventar nuevos usos para las herramientas culturales (Rockwell, 2000). La co-construcción hace referencia a "todo lo que producen los sujetos que se encuentran en la escuela, al interactuar entre sí y al trabajar con los objetos culturales en ese espacio" (Rockwell, 2000: 20). En esta co-construcción cotidiana, las maestras suelen elaborar y reformular las contribuciones de sus estudiantes (por ejemplo, como respuesta a las preguntas de la profesora) para aclarar lo que se ha dicho en beneficio de los demás y también para establecer relaciones entre el contenido de los enunciados de los estudiantes y la terminología técnica del currículo (Candela, 1991, 2006; Lemke, 1997; Mercer, 1997). Bajo ciertas circunstancias, los docentes promueven la reflexión mediante algunos recursos, como argumentar, solicitar ejemplos, devolver las preguntas. El uso de estas estrategias parece ser común en las aulas, a pesar de que los estilos de enseñanza y las maneras de organizar las clases varían en función del contexto institucional, material, cultural y político. Aquí también es notable lo que los niños "hacen con la vida escolar, y las formas en que contribuyen a formar a los maestros" (Rockwell, 2000: 20).

El lugar que ocupan las ideas de los niños — relacionadas con sus prácticas culturales, las preguntas que se hacen y las formas de vivir el mundo social y natural- es importante, sobre todo, porque son sujetos en proceso de tomar decisiones y de reapropiarse de la experiencia 
vivida (Rockwell, 2006). En este sentido, el concepto de apropiación, que pertenece al pensamiento de Ágnes Heller (1985) relativo a la historicidad de la vida cotidiana, me permitió reconocer algunas prácticas y sentidos de los actores educativos en relación con la construcción de conocimiento ambiental. Para Rockwell (2005), dicha noción sitúa la acción en las personas que toman posesión de los recursos culturales disponibles y que los utilizan. También alude a la cultura arraigada en la vida cotidiana, en prácticas, imágenes y palabras, tal y como son experimentadas por las personas. Asimismo, dicho concepto es afín a la perspectiva antropológica que define la cultura como compleja, múltiple, situada e histórica.

\section{El encuentro de explicaciones: las ideas de niñas y niños sobre contenidos ambientales}

Como mencioné al inicio, los análisis de interacciones que presento corresponden a las actividades realizadas en el Proyecto Ambiental en Educación Primaria para cuarto grado. En este escrito solo empleo la denominación ambiente, y no medio ambiente, porque es la más utilizada por los niños y la profesora. También es la más referida en los libros de texto de Ciencias Naturales y Formación Cívica y Ética, donde medio ambiente aparece solo como referencia a alguna institución estatal u organización internacional que ha asimilado esta palabra en sus siglas (ej., la Secretaría de Medio Ambiente y Recursos Naturales, la Comisión Mundial sobre el Medio Ambiente y el Desarrollo, o el Programa de las Naciones Unidas para el Medio Ambiente). También aclaro que en el desarrollo de los contenidos prima la palabra ambiente y, en las clases, la profesora a menudo se refiere a esa noción. Estas cuestiones me generaron inquietud en torno al uso y sentido de esas denominaciones. En diversos artículos de investigación, documentos de trabajo e informes técnicos de EA se utilizan ambas palabras como si fueran sinónimos. En el lenguaje especializado se ha instituido la noción medio ambiente como una manera de introducir la relación sociedad-naturaleza; no obstante, algunos planteamientos, como el de Pacheco Muñoz (2005: 30), sostienen que la palabra ambiente "representa una categoría social constituida por comportamientos, valores y saberes; el ambiente - como una totalidad compleja y articulada - está conformado por las relaciones dinámicas entre los sistemas natural, social y modificado". Pero esta situación conlleva una discusión etimoepistemológica que no abordo; sin embargo, es evidente mi posicionamiento.

En las conversaciones con estudiantes pregunté qué entendían por ambiente, medio ambiente y naturaleza. Para ellos, el ambiente es "lo que está aquí [señalan el jardín de la escuela], todo", "es el dióxido de carbono". Otros dijeron que el ambiente es el aire, las nubes, el cielo. Algunas estudiantes comentaron que "el ambiente está contaminado" porque hay basura, casas, humanos, extinción de animales; que el ambiente "está dañado por nosotros porque tiramos basura, por andar en carros, por comprar cosas", "porque queman y no reciclan", "porque hay guerras, por las bombas", "por las fábricas". También indicaron que "el ambiente está bonito y 
limpio", "es todo lo bonito porque hay animales". Por otro lado, expresaron que el medio ambiente es "la naturaleza, nosotros", "todo lo que nos rodea, el mundo". Una alumna preguntó "¿el medio ambiente es lo que está a la mitad?"; otros manifestaron confusión: "no entiendo, ¿son lo mismo?", "no sé qué sea medio ambiente, ¿es igual a ambiente?", “son las personas y la naturaleza?" o dijeron que no sabían. Para muchos estudiantes, naturaleza, ambiente o medio ambiente representan lo mismo. Otros niños diferenciaron ambiente y naturaleza: el primero es el planeta, las personas, la vida, el medio; el segundo son plantas, animalitos y árboles.

Los estudiantes hicieron constantes referencias a un ambiente contaminado. Pareciera que es una idea de que viven en un lugar sucio. A saber, Coyoacán es una Delegación con diversos problemas de acumulación de desechos sólidos en distintos puntos, sobre todo en las periferias, dado el ineficaz servicio de recolección por parte de la administración delegacional:"Por mi casa no tenemos un eficiente servicio de recolección de basura", me comentó la maestra Perla; "hay mucha basura por donde vivo", dijo una estudiante. Esta problemática apareció con suma recurrencia en las secuencias que presento. Además, dentro y fuera de los espacios escolares también se aludía de maneras específicas y reiteradas a la acción de las personas sobre los espacios que transitan. Si bien en los niños conviven sentidos divergentes de ambiente, predominó una idea de que este es perjudicado por la contaminación donde algunas actividades humanas son las causas que las originan. Estas ideas de ambiente involucraron los elementos estructurales de la sociedad y de las redes de procesos que tejen la actividad antrópica con los aspectos naturales, institucionales, políticos y culturales; es decir, el "ambiente no es la ecología, sino la complejidad del mundo" (Leff, 2006: 13).

Con estas interrogaciones pretendí recuperar algunos contenidos estudiados en otras sesiones de clase, para después relacionarlos con las ideas de los niños sobre los conceptos de desecho y basura. Además, en la secuencia que presento más adelante, muestro parte de una exposición sobre las explicaciones de los estudiantes cuando expusieron sobre "¿qué son los desechos?". Listaron una serie de comentarios sobre la noción desecho, visto por ellos como algo que se genera diariamente o que es la basura producida por las actividades humanas. En términos generales, hay cierta tendencia a señalar los desechos como desperdicios o sobrantes de las actividades humanas, algo que se genera y se desecha porque ya no sirve a las personas; es decir, que su generación es consecuencia de las actividades antropogénicas. Sin embargo, esto no significa que para los niños esos desechos no puedan configurar otro recurso o ser utilizados por otra persona de manera distinta del que los genera. Más tarde, Perla habló sobre la reutilización de la basura. Ella utilizó como ejemplo las botellas, principalmente aquellas a las que se les puede dar otro uso o son "retornables". En cierto momento, un alumno, Arath, pidió participar y explicó: 


\section{Secuencia 1}

68 Arath: Cuando fui a Querétaro fui al parque ecológico, fui y había botes de basura, pero los estaban reciclando [...] amontonaban como si fuera un árbol.

[Fragmentos omitidos]

72 Cristal: Yo vi en Navidad, en un Soriana de Acapulco, un árbol de Navidad con puras botellas de la Coca.

(al mismo tiempo que representa un árbol con su brazo)

73 Lupita: Y también en la tele salió que una escuela, o creo que en un orfanato, tomaron botellas verdes y rojas y así, e hicieron un arbolote y en la punta tenía latas brillantes y doradas.

74 Perla: Muy bien, esos son ejemplos de reutilizar o también esas botellas las vuelven a usar y vuelven a servir.

75 Cristal: En vez de comprar otra, pues ya se usa esa.

76 Perla: Por eso en el caso de las botellas [...] hay botellas que se llaman "retornables" $y$ entonces con esas no estamos generando basura.

Reg. $N^{\circ} 4 \cdot 20 / 02 / 15$.

Tanto estudiantes como maestra movilizaron ejemplos que han observado en diversos espacios de su cotidianidad: lo que vieron en la televisión, en algún parque o centro comercial. Eventos de la vida diaria que parecen propiciar su participación en la co-construcción del contenido. A partir del ejemplo que empleó la profesora (las botellas), Arath retomó lo que observó en un parque ecológico para indicar que reciclaron las botellas. Posiblemente relacionó esa situación de amontonamiento con reciclaje ("pero los estaban reciclando"); es decir, para él la acción que mira no era la de reutilización. Tanto el ejemplo de la profesora como el de Lupita, explicitan que las botellas fueron utilizadas para otro fin, por lo que después, la maestra y Cristal relacionaron los ejemplos a partir de una sola idea: volver a usar las botellas (líneas 75, 76). Para ellas, la mejor forma es reutilizarlo con otros fines, como hacer un "árbol con botellas", por ejemplo. Perla relacionó esas prácticas de uso de las botellas con la idea de que así "no estamos generando basura" por ser "retornables" (véase la línea 76).

El contexto social (el parque ecológico) y los medios de comunicación (la tele) proporcionaron información que aporta a la construcción de conocimiento sobre algunas prácticas ambientales que los estudiantes observaron. Estos eventos y acciones proveen elementos y experiencias de distintos tiempos y espacios que se vuelven locales y se socializan en el aula. Ellos se apropiaron de elementos de su realidad cotidiana, que fueron recuperados por la docente. La conexión con experiencias pasadas que maestra y alumnos realizaron, fue un modo de articular los conocimientos con los contenidos de la clase (ej., "construir habilidades y actitudes positivas asociadas al ambiente"). También, Perla orientó las observaciones estudiantiles para fomentar prácticas de reutilización y, con esto, lograr una co-construcción de la noción reutilizar. Los estudiantes interrelacionaron los elementos (botellas) que la maestra mostró para representar un problema con lo que recuperaron de sus observaciones fuera de la escuela y, así,

Diálo@os sobre Educación año 11 | número 20 | enero-junio 2020| ISSN 2007-2171 
otorgar sentidos a las nociones que se plantearon en la clase (líneas 68, 76). Son aspectos que se vuelven públicos y compartidos, producto de la socialización de experiencias en diversos espacios que transitan.

En otra sesión de clase, Perla explicó dos consignas. Primero, que los estudiantes hagan un recorrido de observación del espacio del aula y registren en su cuaderno un listado de la basura que se generó en la jornada escolar. Luego, como tarea "deben hacer una lista [...] caminan a su casa y se llevan su cuadernito. Los desechos que vayan viendo en su camino los van a ir anotando" (Reg. N 5. 23/02/15). Los niños comenzaron la actividad dando un recorrido por los pasillos entre los pupitres, donde observaron el suelo con cierto detenimiento. Después, anotaron las basuras tiradas allí. Se escucharon comentarios y murmullos: "anota eso", "hay papeles, lápiz", "veo comida", "esa basura tú la tiraste". Minutos más tarde, la actividad fue interrumpida por el timbre de la escuela. La maestra me dijo que no realizaría comentarios del ejercicio, porque daría continuidad a esa tarea con la observación del patio de la escuela, como describo enseguida:

Formados en pequeños grupos, niñas y niños miran los desechos que están tirados en el patio y los anotan para clasificarlos. Algunos dicen: "mira, allí hay popó", "Envases, papel, comida, desechos", "iMe encontré una cuchara, anota eso!". Una alumna, Mar, escribe casi todo lo que se encuentra tirado. Otro grupo de tres niñas recogen algunos desechos, los miran con detenimiento y anotan en sus libretas; vuelven a tirar los objetos. "Alberto, dame mi parte de la basura", se escucha la voz de una niña. " ¿Lo dejo o lo recojo?", le pregunta Luis a Mar en el instante que observan unos platos desechables. Mar le responde: "allá hay más".

Me acerco a unos estudiantes y pregunto:"oigan niños, ¿aquí en la escuela separan la basura?". Varios niños comentan: "nooooo", al mismo tiempo que mueven la cabeza de lado a lado al ritmo de sus respuestas. “¿Creen que debería separarse?", aclaro. Ellos responden con un sí ruidoso. Cristal indica: "para que se pueda reciclar". Otra alumna agrega: "para que no se contamine el ambiente". Cristal la sigue: "se puede reciclar». "¿Por qué creen que aquí no se separa la basura?", insisto. Cristal se muestra pensativa y algunos niños se miran el uno al otro. Mar se lleva su lapicero a la boca y piensa. Se escucha una voz: "porque es una escuela y aquí aprendemos"; otra niña comenta: "porque no hay frutas". Pregunto: " $¡ Y$ por ser una escuela no debería de separarse [la basura]?". Mar responde que no, otros le siguen con la misma contestación; Cristal duda: "no sé". Mar cambia de opinión: "sí se debería de separar". Le pregunto por qué y ella explica: "porque tenemos que reciclar algunas cosas como las hojas o papel". Se escucha la voz de otra alumna que dice "como las botellas". Agrego: “¿les gustaría que aquí en la escuela se separara la basura?". Todos respondieron que sí. Comento: "oigan, la basura que se encuentran tirada, ¿la recogen?». Lucía expresa sin pena: "a veces, a veces", también se escuchan varios "no" y otros pocos "sí". Insisto, “'Por qué no?" y Mar responde:"¡Porque da hueva!". Una compañera la delata:“Es que ella es muy floja. No sabe lo que hace".

Reg. $N^{\circ} 5.23 / 02 / 15$. 
Los estudiantes observaron las condiciones del patio escolar después de una jornada de recreo. En las actividades de observación se conjugaron dos sentidos: la basura que fue generada y la basura tirada en el piso. El primero, relacionado con una atribución de responsabilidades ("esa basura tú la tiraste"); el segundo, sobre aquel objeto material que si se conserva en la mano no es basura, pero en el instante que se arroja al piso o al bote de basura se convierte en basura (el lápiz tirado en el piso). La antropóloga Mary Douglas (1973) nos dice que, por ejemplo, los zapatos no son sucios en sí mismos, pero es sucio colocarlos en la mesa del comedor. También es interesante cómo los niños reconocen la escuela como una instancia formativa ("porque es una escuela y aquí aprendemos"). En este caso, hay un sentido compartido que manifiesta algunos de sus hábitos (tirar basura) que podrían pasar de tirar la basura "donde sea", por una cuestión actitudinal ("da hueva"), a operaciones favorecedoras (reciclar los desechos).

La tarea de observación de las condiciones de la calle en el camino a casa, donde los estudiantes anotaron la basura que encontraron para después clasificarla, y la actividad posterior (observar el patio de la escuela) que implicó que llevasen referentes (ej., envolturas, papel, latas), se realizó para que ellos contrastaran lo que vieron en el aula, el patio escolar y la calle. Así, los estudiantes pasaron de las definiciones a la observación y clasificación de los desechos. Para la docente, la idea es que ellos "sean conscientes de las cantidades de desechos que se generan y tengan hábitos de no tirar basura" (Perla. Comunicación personal, 23/02/15). También se filtra la relación de la sociedad con el ambiente y la denuncia social y mediática de que la gente tira la basura por "falta de educación" o desinterés ("es que ella es muy floja. No sabe"). Estas prácticas forman parte de la realidad cotidiana de muchas escuelas. Aquí, la idea de arrojar al piso un objeto considerado basura está culturalmente vinculada a la de desorden y suciedad (véase Douglas, 1973). Es decir, se asigna un sentido de orden y limpieza a la idea de contaminación. Cuestión que, además, se relaciona con la posición moral y de consumo, de por qué tiramos basura, que podría explicarse por los desechos generados en las sociedades capitalistas.

En la siguiente interacción, Perla solicitó a sus estudiantes que narraran lo que observaron en la calle. Enseguida, mencionaron lo que encontraron: "Yo vi naranjas tiradas, lápices, envolturas", "Yo vi en la calle cáscaras de naranja, también aquí [en la escuela]”, "Bolsas y papeles tirados”, "estaba muy cochina la calle". La docente pasó a observar el avance de cada equipo. Luego, los estudiantes compartieron lo que vieron: "Por donde vivo hay un basurero", " ¡vasos de papel en la calle!", explicaron algunos. "Ya pusimos bolsas, quítalo, por plástico", expresó una niña a sus compañeros. Una alumna le preguntó a otro cuántos objetos encontró en su recorrido por las calles. Él respondió que muchos, y ella lo invita a escribirlos en el papel. Un niño señaló algunos desechos que están en el piso del salón: "anotemos esos"; sus compañeros escriben. Lupita

7 Como mencioné anteriormente, en los salones de clases los niños trasladaron la idea de ambiente "sucio" y "cochino" debido a la falta de servicios de recolección de desechos sólidos en diversas colonias de la Delegación. 
mostró su hoja de trabajo a la maestra, quien le dice: "Está bien". Otra estudiante vio una hoja de papel, la recoge, la hace bolita y la tira en el bote de la basura. "Cajas, cajas, anota cajas", insistió Lupita a su equipo. Perla solicitó terminar esa parte de la actividad y se acercó al pizarrón:

\section{Secuencia 2 \\ 142 Perla:}

143 Arath: Diferencia que en un lugar hay más [basura] que en otro. Por ejemplo, en el salón hay menos basura que en la escuela, y en la escuela hay menos basura que en la calle.

144 Perla: ¿A qué creen que se deba eso?

145 Mar: Que la calle es un lugar público, hay muchas personas que arrojan cosas porque compran y compran.

146 Grupo: Se escucha que otros niños dicen: "son lugares privados".

147 Perla: $\quad$ Exactamente. El salón es un lugar pequeño y, aún así...

148 Alumna: ¡Hay mucha basura!

149 Perla: Sí, exactamente, siendo un lugar pequeño se genera demasiada basura: basura de lápiz de cuando le sacan punta, papel de las hojas, y si ahorita observan, también hay cajas de leche de los desayunos, cáscaras de naranja de cuando les dan naranjas como hoy, leche que la empacan y la tiran, envolturas que traen de su casa de distintos productos y popotes que son también de los desayunos. Ustedes tienen aquí un bote de basura (se acerca al bote y lo señala), ¿y para qué sirve el bote de basura? (señala a Cristal).

150 Cristal: (Con cierto tono de duda) Para tirar la basura que generamos.

151 Perla: Exactamente. En el bote de basura tenemos que tirar todos los desechos: esto y eso y todo lo que está aquí (señalando el pizarrón), no tendría por qué estar en el piso, siendo que ustedes tienen un bote de basura. Hemos hablado, porque no ha sido la primera vez, [...] acerca de la contaminación, el consumismo y todos los daños que ocasionamos al ambiente, entonces, ¿por dónde debemos de empezar?

$\begin{array}{lll}152 & \text { Alumno: } & \text { Por la basura. } \\ 153 & \text { Perla: } & \text { ¿Por la basura de dónde? } \\ 154 & \text { Alumna: } & \text { Del salón (tono de voz bajo). }\end{array}$

A partir de algunas preguntas, la maestra indagó las ideas de los estudiantes sobre los contextos observados en términos de basura y de contrastes. La respuesta Arath indicó diferencias entre las cantidades de basura que se generaron en el salón, la escuela y la calle. Mar explicó que en la calle hay más basura porque es un lugar "público". A través de estas actividades, el tratamiento que la maestra hizo del contenido suscitó diversos relatos estudiantiles sobre los espacios que transitan. A partir del comentario de Arath (línea 143) y la pregunta de la maestra 
("¿A qué creen que se deba eso?"), se originó cierto consenso entre algunos estudiantes sugiriendo que en los lugares "privados" hay menos basura (línea 146, cursivas). ${ }^{8}$

Aquí planteo dos cuestiones. Por un lado, la idea de lo público y lo privado se configura como espacios donde una misma acción humana puede generar resultados distintos. Es decir, se asignan ciertos sentidos de que en las calles —en tanto espacio público- hay más densidad de población ("la calle es un lugar público, hay muchas personas") y las normas sociales operan de manera distinta a las del hogar o, en este caso, de la escuela (véanse las líneas 145-151). De ahí que algunos estudiantes, como Arath y Mar, deduzcan que las personas tiran más basura, a partir de la observación de estos ("en un lugar hay más [basura] que en otro"). También denunciaron algunos hábitos de consumo de las personas ("hay muchas personas que arrojan cosas porque compran y compran"). Por otro, la profesora relacionó lo "privado" con la idea de dimensión ("lugar pequeño"). No obstante, denunció que, a pesar de ello, las condiciones del aula no son las adecuadas: "Todo lo que está aquí no tendría por qué estar en el piso, siendo que ustedes tienen un bote de basura". El comentario de Mar generó que la maestra cuestionara dicha idea pues, a pesar de que el salón es un espacio más pequeño, "aún así...", y dejó abierta la idea, que luego María completó: "¡hay mucha basura!" (líneas 147-148). Asimismo, la docente aludió a ciertos elementos (el bote de basura) como una manera de "conscientizar", indicando a sus estudiantes la utilidad de ese objeto. Además, sobre las causas (consumismo) y las consecuencias (contaminación) de que haya mucha basura; también atribuyó responsabilidades a esas prácticas ("Ios daños que ocasionamos al ambiente", línea 151).

En esta reflexión, vale tomar en cuenta las continuidades y la influencia social que atraviesan los espacios de las escuelas y que cambian con el tiempo (Rockwell, 2000). Es decir, no se trata solo del influjo de adultos sobre niños, sino que hace hincapié en las relaciones entre pares, el contexto social y los medios. Me refiero, por ejemplo, a que algunas niñas ven videos de Internet y documentales de televisión: "Me gusta ver videos de YouTube y Discovery, porque pasan lo que daña el planeta", dijo Mar. En otro momento, Cristal me comentó que observó un video donde se mostraba cómo "las fábricas contaminaban porque desechaban cosas al río" y otro donde "mataban a unos cerditos y era cruel" (Comunicación personal, 24/02/15). ${ }^{9}$ También, los estudiantes construyeron cierto sentido común sobre la actividad humana en términos de civilidad y actividad, movilizaron conocimientos de un ambiente que incorpora elementos socioculturales sobre las formas de vivir de la sociedad, su interacción en el ambiente y el debate

8 Más adelante, en el desarrollo de la clase, ese consenso fue retomado por la maestra Perla al comentar que "en la calle, ya vimos que se genera muchísima basura, ¿por qué?, porque ahí, como ya lo comentaban, hay todavía más gente: adultos, niños de todas las edades, es un lugar más grande [...] y ustedes ven todo lo que se tira." (Reg. № 5. 23/02/15).

9 Tales contenidos pueden contrastar con aquellos donde la publicidad comercial induce precisamente el patrón consumista. Además, en estas clases algunos recursos, como documentales y cortometrajes, fueron utilizados por la maestra Perla como una vía a "contenidos distintos de los libros de texto" (Comunicación personal, 24/02/15).

Diólo pos sobre Educación año 11 | número 20 | enero-junio 2020| ISSN 2007-2171 
público de que la basura se ha convertido en un problema ambiental. Estos sentidos se introdujeron hacia la construcción de cierta conciencia, por ejemplo, sobre los hábitos de consumo ("porque compran y compran", línea 145).

En la secuencia que sigue, como respuesta a las preguntas de Perla, los estudiantes formularon explicaciones sobre algunos fenómenos. Puede notarse la preocupación de la maestra para que ellos se apropien de acciones como tirar los desechos en los lugares correspondientes y generar conciencia del cuidado ambiental. Al inicio de la clase, los niños realizaron una actividad que consistió en dar un recorrido por el patio de la escuela para observar y clasificar la basura generada durante el recreo, como vimos en el registro de lo observado en el patio de la escuela y en la secuencia 2. Cuando pasaron al salón de clase, Perla proporciona una hoja a los estudiantes para que escriban los desechos que observaron y, posteriormente, presentar esa información. Más tarde, la profesora expuso acerca de la basura que se generó en el salón, en la escuela y en la calle:

\section{Secuencia 3}

162 Perla: [...] En el bote de basura se tienen que tirar todos los desechos. Esto y eso y todo lo que está aquí (señala los ejemplos del pizarrón), no tendría por qué estar en el piso, siendo que ustedes tienen un bote de basura. Hemos hablado, porque no ha sido la primera vez, [...] acerca de la contaminación y todos los daños que ocasiona al ambiente, entonces, ¿por dónde debemos de empezar?

163 Alumno: Por la basura.

[Fragmentos omitidos]

171 Cristal: Porque yo, de toda la basura que tiramos en el salón, en la calle y en la escuela hace que en la capa de ozono se hagan hoyos y luego ya no vamos a tener y todo el calor nos van a entrar los rayos así (gesticula con ambos brazos)

172 Perla: Exactamente, estamos terminando con lo que nos protege.

173 Grupo: (casi la mayoría) la capa de ozono.

174 Perla: ¿Por qué? Porque generamos basura, porque todavía no adquirimos esa conciencia de todo lo que compramos y de tirar la basura en donde debe de ser (señala el bote de la basura). En la calle, ya vimos que se genera muchísima basura, ¿por qué? Porque ahí, como ya lo comentaban, hay todavía más gente: adultos, niños de todas las edades, es un lugar más grande.

175 Mar: $\quad$ Es un lugar público.

176 Perla: $\quad$ Y ustedes ven todo lo que se tira.

177 Alumno: Yo vi más.

Reg. No 5. 23/02/15.

En el análisis de esta secuencia, las ideas de algunos estudiantes muestran que la contaminación por basura es una problemática ambiental que daña la capa de ozono (líneas 171, 173) y se debe comenzar por no tirar basura (líneas 162-163). Esto conlleva dos aspectos: primero, el consumo y la basura que se genera; luego, el daño a la capa de ozono. Aquí puede entenderse 
que los estudiantes construyeron explicaciones sobre el fenómeno del daño a la capa de ozono y cuáles son sus causas, que argumentaron mediante lo que observaron en su cotidianidad. Los estudiantes movilizaron explicaciones de que la reducción de ozono es ocasionada por la contaminación por basura. Como estos niños, muchos llegan a las clases de ciencias con interpretaciones de los fenómenos que estudian, aunque no hayan recibido ninguna enseñanza sistemática al respecto (véase Driver et al., 1986). Asimismo, construyeron esas ideas a partir de las experiencias en todos los aspectos de la vida diaria, por ejemplo, de las conversaciones con otras personas, de los espacios que transitan y de los medios de comunicación.

Cristal trasladó una problemática ambiental donde la contaminación por basura tiene relación con el debilitamiento de la capa de ozono. Es decir, para ella "toda la basura que tiramos en el salón, en la calle y en la escuela" contribuye a la contaminación atmosférica (línea 171). La idea que la alumna elaboró - la generación de residuos provoca que "en la capa de ozono se hagan hoyos [...] y todo el calor nos van a entrar los rayos asi" - se acerca a la explicación de que la pérdida de ozono estratosférico produce niveles más altos de radiación ultravioleta y llega a la superficie terrestre a causa del aumento del "agujero" de ozono. Luego, los comentarios de los niños fueron ampliados por la maestra, quien explica que "estamos terminando con lo que nos protege", refiriéndose a que la capa de ozono es un "escudo que nos resguarda de la radiación ultravioleta".

La explicación de la profesora, de que se observa más basura en la calle porque es "un lugar más grande", fue incorporada por una estudiante. Ella retomó ese elemento para seguir con la línea de reflexión: en la calle se contamina más porque es un espacio público. Tal vez porque hay mayor densidad de población y las normas sociales operan de manera distinta a otros espacios, como el escolar o el familiar. De ahí que la profesora expresa que en la calle se genera "muchísima basura" porque hay "más gente: adultos, niños de todas las edades, es un lugar más grande". Luego les comentó que ellos "ven todo lo que se tira" (líneas 174-176). La maestra incluyó esa reflexión al mencionar que ellos ven todo lo que se tira en la calle, por lo que incitó a que Matías aludiera a su experiencia: "yo veo más" (línea 177). Estas interacciones indican que los conocimientos y las preocupaciones ambientales empiezan a extenderse a la sociedad. Además, se relacionan con los hallazgos de Dos Santos Silva y Pegado Abílio (2014), quienes encontraron que las ideas de los estudiantes destacan aspectos de desequilibrio ambiental, como la contaminación y deforestación en un sistema de manglares en una comunidad de Brasil.

Pareciera que estos intercambios fueron una invitación docente al alumnado a reflexionar y actuar. La profesora se apropió de un discurso social, político y pedagógico para "influir" en las prácticas y acciones cotidianas de los niños hacia el "cuidado ambiental". Por ejemplo, depositar los desechos en los lugares adecuados. Un discurso que promueve el cambio de hábitos: "no tendría por qué estar en el piso, siendo que ustedes tienen un bote de basura", "porque todavía no adquirimos esa conciencia de todo lo que compramos y de tirar la basura en donde debe 
de ser" $y$ "en la calle, ya vimos que se genera muchísima basura". Aquí también se yuxtaponen, como vimos en secuencias anteriores, las idea sde limpieza y contaminación.

La concordancia entre las actitudes y los conocimientos evidencia comportamientos cercanos a los previstos (lo que el alumnado dice en relación con lo que hacen) o deseados por un currículum escolar que espera que los niños construyan conocimientos, comportamientos y actitudes que beneficien al ambiente (SEP, 2011a). Observamos que la profesora, precisamente, orientó a los estudiantes para que se apropiaran de hábitos considerados benéficos para el ambiente; pero también otorgó un sentido ético-moral a dichas prácticas: que "los niños valoren las consecuencias de sus actos" (Perla. Comunicación personal, 23/02/15). Es un acto de recurrir a la tarea que pretende sensibilizar a los niños mediante prácticas que conduzcan a la reflexión sobre la relación ética entre la sociedad y la naturaleza. Sin embargo, la concordancia entre los conocimientos y las acciones de las personas no siempre es coherente, porque conviven sentidos divergentes sobre la idea de ambiente.

En el siguiente ejemplo veremos cómo una alumna movilizó un suceso que observó en la calle, aportando otros matices y elementos a nuestro tema en cuestión. Esta secuencia se originó cuando la profesora hizo comentarios en torno a las ideas de sus estudiantes acerca de dónde provienen algunos desechos. Cuando Perla dijo "las cáscaras de naranja", Ana denunció a su compañera Jimena, quien se había comido una naranja: "te dijeron que las recogieras, no que tiraras más [cáscaras]". Enseguida, Jimena se puso de pie y comenzó a recoger sus desechos. Posteriormente, y sin la solicitud docente, Cristal narró una anécdota que orienta la siguiente interacción:
Secuencia 4
330 Cristal:
Yo una vez estaba con mi prima, estábamos en la calle sentadas [...] Entonces, una señora estaba sentada al lado de nosotros y se comió quién sabe qué y los echó a la coladera.
331 Perla: Imagínense, ¿qué otro problema genera el que yo tire la basura?
332 Grupo: (a coro) ¡Inundaciones!
333 Cristal: $\quad$ Y es que si tiras basura provocas inundaciones porque se tapan las coladeras y cuando llueve ya no se puede ir por ahí el agua, porque ya está tapada.
334 Alumno: ¡Y se inunda!
335 Perla: Y eso está generando otro problema que son las inundaciones.
336 Cristal: En mi casa, allá en Naucalpan donde vive mi mamá, todas las coladeras se taparon una vez... estaba lloviendo mucho, se tapó por tanta basura y se inundó.

Reg. N ${ }^{\circ} 5.23 / 02 / 15$.

Cristal elaboró diversas explicaciones y movilizó algunas ideas para exponer como ejemplo una situación que observó en el barrio donde vive. La alumna estableció una asociación entre lo que observó y el tema de la clase (clasificación de la basura). En su narrativa, Cristal denunció la acción de una persona que estaba consumiendo algún producto cuya envoltura tiró a la 
alcantarilla de un espacio considerado público por algunos estudiantes. Aquí pareciera que el alumnado reflexiona lo que observa en su vida diaria a partir de lo que ha experimentado y lo vincula con los contenidos que se discutieron en las clases (por ejemplo, del tema "¿Adónde va la basura?"). Es un proceso que les permitió repensar la experiencia de ese momento concreto. La narrativa de Cristal también movilizó al espacio del aula una acción humana hacia el ambiente: tirar basura (línea 330). Así, los estudiantes trasladaron sus vivencias para otorgar sentido al contenido escolar y expresaron una opinión (crítica) acerca del comportamiento de algunas personas adultas. En este caso, asimismo, se trata de un problema ocasionado por tirar basura que, por ende, ocasiona inundaciones.

Partiendo de la anécdota relatada por Cristal, Perla intervino para que los niños piensen en los problemas que provoca arrojar la basura en la calle. Algunos dicen a coro: "inundaciones". Perla aportó a la idea de por qué el agua no se va por las coladeras al mencionar que es porque el sistema de drenaje está tapado a causa de la basura que tira la gente (líneas 332, 333, 335). Por lo que, como dice Candela (2006), al introducir este problema, no incluido en el libro de texto, la maestra desplaza al libro como única fuente de conocimiento y le da autoridad a los saberes que los niños movilizan desde otros ámbitos.

Las explicaciones de los niños evidencian los problemas que se provocan al tirar basura. En este caso, después de que la maestra realizó una pregunta que invita a pensar "otros problemas", Cristal recurre a lo que ha observado para comentar que en la casa donde vive su mamá "todas las coladeras se taparon una vez... estaba lloviendo mucho, se tapó por tanta basura y se inundó". Quizá hizo referencia a las acciones de otras personas porque en esta clase la maestra denunció que tanto ellos como otras personas tienen hábitos que perjudican al ambiente. Otro de los elementos de esta secuencia es que la profesora posibilitó que la reflexión de los niños vaya más allá del contenido previsto (i.e., el tema de la clase es la separación de la basura), tomando como referencias sus vivencias. En algunos casos como este y sin la solicitud docente, los estudiantes establecieron relaciones con el contenido a partir de lo que saben $y$, al mismo tiempo, modificaron el contenido presentado.

En otra sesión de clase, como parte del Proyecto Ambiental en Educación Primaria, los estudiantes elaboraron carteles para presentar sus reflexiones acerca de lo que discutieron y trabajaron. Esta actividad se organizó de tal manera que ellos se agruparon en equipos de tres a cinco integrantes para trabajar en el piso del salón (así lo solicitaron). Perla les pidió que registren en el papel bond qué son los desechos o la basura, qué es y qué tipos de basura conocen. Los alumnos comenzaron a trabajar. Luego, me acerqué a un equipo conformado por Arath, Alberto y Mario, quienes tuvieron la siguiente interacción:

Diólo@os sobre Educación año 11 | número 20 | enero-junio 2020| ISSN 2007-2171 


\section{Secuencia 5}

68 Arath: (Le comenta a Alberto) Recorto a dos personas que están recogiendo basura y podemos poner algo que diga «no tires basura, por favor»

(Alberto lo mira y asiente con la cabeza. Después, comienza a hojear las revistas que tomaron del librero).

[fragmentos omitidos]

70 Alberto: ¿Y si le hacemos el Sol alrededor de la Tierra?

71 Arath: Sí, lo está dañando con los rayos UV

72 Arath: Haz el globo donde va a hablar... con un lápiz, dale el lápiz.

73 Mario: Con este color.

74 Alberto: Es que...

75 Arath: No, no... nada más haz el globo.

76 Alberto: Nada más haz el globo y luego...

77 Arath: ...pero hazlo grande (al mismo tiempo que mira a Alberto)

78 Alberto: (representa en el papel lo que dice) Hazlo así.

79 Mario: ¿Un globo?

80 Arath: Sí, como si hablara.

81 Alberto: De esos que ves en los comics... de esos de que ves en los comics.

Reg. No 9. 13/03/15.

Arath procuró que el cartel diera un mensaje orientado hacia el cuidado del planeta evitando "tirar basura", que tiene relación con el contenido presentado en el video de YouTube Contaminación ambiental para niños y en otra sesión donde se abordó el tema "¿Adónde va la basura?". Los niños involucraron diversos elementos para hacer llamativo su cartel al pensar en las dimensiones, los elementos que van a dibujar, así como las características de este (líneas 7281). Es interesante la contribución de Arath, porque evidencia cierto conocimiento de que el Sol "está dañando [a la Tierra] con los rayos UV". Cuestión cercana al planteamiento científico de que el deterioro de la capa de ozono ha provocado que la radiación UV emitida por el Sol impacte en nuestro planeta. Este fue el producto final:

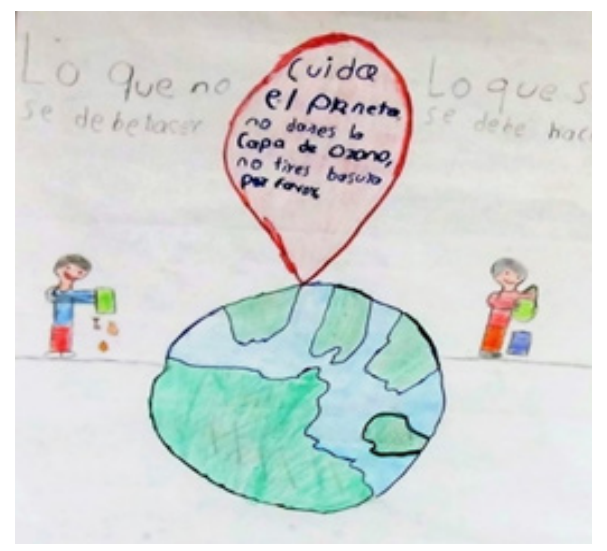

Figura 1 
En los demás equipos, los estudiantes dibujaron elementos como, por ejemplo, nubes, árboles, bolsas; otros propusieron, revisaron o recortaron elementos de algunas revistas que tomaron de la biblioteca del salón. Tiempo después, Arath le pidió a la maestra que vea sus avances. La profesora observó. Después les dijo que se ocuparan "de los desechos que originaron con sus recortes"; aquí ella pasó a la práctica de lo dicho en diversas ocasiones. También pareciera que Perla retomó la preocupación de los niños por el planeta (figura 1) para que generen hábitos de limpieza en el salón. Más tarde, los estudiantes expusieron temas relacionados con, por ejemplo, "utilicemos la bicicleta para no contaminar el aire" o "cuidemos el agua", por mencionar algunos. Arath, Alberto y Mario expusieron ideas sobre "lo que no se debe hacer y lo que sí se debe hacer para cuidar el ambiente". Ellos se organizaron para explicar el contenido en torno al dibujo que representa el planeta Tierra y el globo de diálogo que lo acompaña, cuyo mensaje "Cuida el planeta, no dañes la capa de ozono, no tires basura, por favor" muestra al grupo lo que ellos tratan de comunicar. Estos niños no prepararon un guion para la exposición, elaboraron sus explicaciones a partir del contenido del cartel. Algunos sumaron ideas en función de lo que charlaron entre ellos y los integrantes de otros equipos, e incorporaron reflexiones en torno a los temas que abordaron en otras sesiones de clase. La profesora contribuyó a la dinámica de interacción con algunas ideas o comentarios de experiencias personales que referían a los temas presentados. Por ejemplo, cuando uno de los equipos habló respecto al uso de la bicicleta como un medio para favorecer el ambiente, la profesora relató una anécdota de cuando utilizaba la bicicleta para trasladarse a algunos sitios y dijo que "era una manera de no contaminar".

Como vimos en líneas anteriores, algunos niños dieron indicios de cierta apropiación de nociones y prácticas planteadas, tanto por la docente como por los contenidos. Para algunos estudiantes, las actividades humanas son las causas que originan la contaminación del aire, el suelo y el agua. Por ejemplo, cuando hicieron referencia a los gases procedentes de las fábricas o la basura que tiramos. En esta aula se movilizaron muchas narrativas de la vida cotidiana, cuestión que muestra un ambiente perjudicado por la contaminación y las acciones de las personas. También hubo una recurrente preocupación por generar acciones de protección ambiental, que apareció en el discurso de estos actores educativos.

\section{Reflexiones finales}

En los análisis se entrevén las huellas que han dejado las distintas contribuciones desde el ámbito social, político, pedagógico y científico para mejorar la enseñanza de la educación ambiental (EA). También para dar explicación (o posibles soluciones) a los problemas ambientales que se han agudizado, al límite de poner en riesgo la sobrevivencia humana en el planeta. Vimos que los estudiantes fueron portadores de experiencias a través de lo que les inquieta, observan, escuchan, leen y hacen: están atravesados por sus vidas cotidianas. Es decir, se advierte el lugar del conocimiento como componente de toda práctica cultural (Gramsci, 1971). Los niños cons-

Diólo@os sobre Educación año 11 | número 20 | enero-junio 2020| ISSN 2007-2171 
truyeron saberes sobre muchas cosas de lo que vivenciaron en diversos espacios y se posicionaron como sujetos críticos de lo que hacen los adultos (y de sí mismos). Estas características aportaron al sentido que ellos asignaron acerca de lo que acontece en los lugares que habitan. El sentido que le otorgaron a los fenómenos estuvo influido por sus ideas y enfocaron sus observaciones en lo que perciben como factores importantes (Driver et al., 1994). Esto es, el conocimiento ambiental pasó de un proceso de reconocimiento, identificación y redefinición a estar disponible para ser empleado ante situaciones que permitieron a los estudiantes comprender y establecer relaciones sobre los diversos fenómenos de la vida diaria.

La dimensión ambiental convive en las escuelas a partir de la movilización de distintas formas de conocimiento ambiental. Aquí la información escolar, en el caso de estas clases, tuvo un papel importante en las ideas y las explicaciones que los niños construyeron al interactuar con el ambiente. Algunos estudiantes se acercaron a un "sentido compartido" de que algunos desechos se pueden incluir en la cadena de consumo humano o que el daño a la capa de ozono es provocado por la contaminación por basura: si tiras basura provocarás inundaciones, es la síntesis más clara de estas cuestiones.

Las interacciones en esta aula se caracterizaron por la construcción de ideas que generaron sentidos diversos sobre la problemática ambiental. La co-construcción de conocimiento supuso una interrelación entre lo que los niños vivieron y lo que la maestra procuró enseñar. Las relaciones que se establecieron entre el conocimiento teórico, el conocimiento de sentido común y la información escolar, evidencia un entramado complejo en torno al contenido curricular. Es decir, los contenidos ambientales fueron co-construidos entre los niños y la maestra. En algunas charlas que tuve con Cristal, Mar y Arath, me dijeron que hablar de esos temas les "motivó" (dicho así por ellos) a pensar lo que vieron en sus colonias o en sus casas. Cuestión que muestra que el conocimiento se construye a partir de una riqueza de motivaciones, búsquedas, descubrimientos, preocupaciones, dudas, certezas y equivocaciones.

En efecto, me parece que la relación que los estudiantes establecieron con los contenidos curriculares evidenció la construcción de conocimientos sobre educación ambiental, aunque esto no se puede precisar en todos los casos. Es decir, no es posible saber el grado de apropiación de los contenidos curriculares por parte de los niños. Sin embargo, es interesante que esas co-construcciones no se dieron sobre la base de distinciones conceptuales, sino en el sentido, las prácticas y el uso social que los participantes le otorgaron al saber ambiental. Esto fue evidente en los intercambios argumentativos entre ellos y cuando defendieron sus opiniones. Ese proceso ejemplifica cómo el alumnado construyó contextos diversos en la interacción; es decir, las condiciones de interacción no se dieron en la mera reproducción de contenidos escolares. Aquí los niños se posicionaron como sujetos que forman parte de la dinámica sociedad-naturaleza. Proceso mismo que estuvo acompañado de creencias y experiencias heterogéneas con y en el mundo, que son aportadoras y referentes de saberes ambientales. No obstante, estos 
elementos están cruzados por procesos y elementos más amplios que se van configurando en el tiempo; pero que también han encontrado tensiones, contradicciones, resistencias y transformaciones en diversos espacios, como el familiar.

En suma, la escuela es un ámbito donde con frecuencia se generan significaciones diversas sobre la cuestión ambiental, aunque a veces contradictorias entre sí. Cuestión que obliga a posicionarse ante estas relaciones a escala cotidiana que conforman la vida escolar y pensar continuamente las configuraciones (en términos de transformación o reproducción) de una dimensión ambiental que no se puede separar del contexto histórico actual — donde hay una fase capitalista signada por la concentración de la riqueza, la explotación de los recursos naturales y la precarización de la vida. Esto genera constantes construcciones y significados que no son estables. Además, aquí se ponen en juego diversas tradiciones y cosmovisiones sobre los fenómenos del mundo y la naturaleza, conjugados con momentos coyunturales que influyen en las ideas de los niños.

\section{Dedicatoria}

A las niñas y los niños, porque cuando miran, piensan, narran, cuestionan, explican, dibujan, juegan, me hacen reflexionar constantemente sobre cómo sienten, perciben e interpretan el mundo de las cosas. Un mundo sensible e inteligible, mundo en permanente movimiento e interacción.

\section{Agradecimientos}

Agradezco la buena predisposición de mi colega y gran amiga, la Mtra. Tatiana Mendoza von der Borch, cuya lectura minuciosa y aportaciones críticas enriquecieron este trabajo. Igualmente, a la Dra. Antonia Candela por acompañarme y orientarme en el proceso de la investigación que originó este escrito.

\section{Referencias}

Candela, A. (1990). Investigación etnográfica en el aula: El razonamiento de los alumnos en una clase de ciencias naturales en la escuela primaria. Investigación en la Escuela, (11), 13-23. (1991). Argumentación y conocimiento científico escolar. Infancia y Aprendizaje, 14(55), 13-28.

(1999a). El discurso de la ciencia en el aula. En Remedi, E. (ed.). Encuentros de Investigación Educativa 95-98. México: DIE-Cinvestav/Plaza y Valdés, 27-53.

(1999b). Prácticas discursivas en el aula y calidad educativa. Revista Mexicana de Investigación Educativa, 4(8), 4.

(2001). Ciencia en el aula. Los alumnos entre la argumentación y el consenso. México: Paidós.

\section{Diólo os}


(2006). Del conocimiento extraescolar al conocimiento científico escolar: Un estudio etnográfico en aulas de la escuela primaria. Revista Mexicana de Investigación Educativa, 11(30), 797-820.

E. Rockwell y C. Coll (2012). ¿Qué demonios pasa en las aulas? La investigación cualitativa del aula. CPU-e, Revista de Investigación Educativa, (8), 1-28.

Chartier, R. (1995). Sociedad y escritura en la edad moderna. La cultura como apropiación. México: Instituto Mora.

Dos Santos Silva, D. y F. J. Pegado Abílio (2014). Percepção discente, escola e cidadania: diálogos entre meio ambiente e educação ambiental em uma escola pública da capital paraibana. Revista Brasileira de Pesquisa em Educação em Ciências, 14(2), 215-223.

Douglas, M. (1973). Pureza y peligro. Un análisis de los conceptos de contaminación y tabú. España: FCE.

Driver, R. (1983). The Pupil as Scientist? Oxfordshire: Open University Press. Guesne, E. y A. Tiberghien (1986). Ideas científicas en la infancia y la adolescencia. Madrid: Morata/MEC.

Squires, A., P. Rushworth y V. Wood-Robinson (1994). Making Sense of Secondary Science: Research into Children's Ideas. Londres: Routledge.

Edwards, D. y N. Mercer (1988). El conocimiento compartido: El desarrollo de la comprensión en el aula. España: Paidós/MEC.

González Gaudiano, É. (2007). La educación ambiental en la escuela latinoamericana en el tercer milenio. La educación frente al desafío ambiental global. Una visión latinoamericana. México: CREFAL/Plaza y Valdés, 109-127.

Goodson, I. F. (1995). Historia del currículum. La construcción social de las disciplinas escolares. Barcelona: Pomares-Corredor.

Gramsci, A. (1971). El materialismo histórico y la filosofía de Benedetto Croce. Buenos Aires: Nueva Visión.

Heller, Á. (1985). Historia y vida cotidiana. Aportación a la sociología socialista. México: Grijalbo.

Lara Corro, E. S. (2018). La construcción social de conocimiento ambiental en aulas de escuelas primarias (Tesis DIE). México: DIE-Cinvestav.

Leff, E. (1998). Saber ambiental. Sustentabilidad, racionalidad, complejidad, poder. México: Siglo XXI. (2006). Aventuras de la epistemología ambiental: De la articulación de ciencias al diálogo de saberes. México: Siglo XXI.

Lemke, J. (1997). Aprender a hablar ciencia: lenguaje, aprendizaje y valores. Barcelona: Paidós.

Mercer, N. (1997). La construcción guiada del conocimiento: el habla de profesores y alumnos. España: Paidós.

Pacheco Muñoz, M. F. (2005). El ambiente, más allá de la naturaleza. Elementos. Ciencia y Cultura, 12(57), 29-33. 
Rockwell, E. (1995a). De huellas, bardas y veredas: una historia cotidiana en la escuela. La escuela cotidiana. México: FCE, 13-57.

(1995b). En torno al texto: Tradiciones docentes y prácticas cotidianas. La escuela cotidiana. México: FCE, 198-222.

(2000). Tres planos para el estudio de las culturas escolares: el desarrollo humano desde una perspectiva histórico-cultural. Interações, 5(9), 11-25.

(2005). La apropiación, un proceso entre muchos que ocurren en ámbitos escolares. Memoria, conocimiento y utopía. Anuario de la Sociedad Mexicana de Historia de la Educación. Barcelona: Pomares, 28-38.

(2006). Los niños en los intersticios de la cotidianeidad escolar: ¿resistencia, apropiación o subversión? Conferencia presentada en el XI Simposio Interamericano de Etnografía de la Educación. Buenos Aires.

(2009). La experiencia etnográfica: Historia y cultura en los procesos educativos. Argentina: Paidós.

Secretaría de Educación Pública (2011a). Plan de estudios 2011. Educación Básica. México: DGMIE/SEP. 